\title{
Assessment of genetic variability among I ndian sheep breeds using mitochondrial DNA cytochrome-b region
}

\author{
A. D. Sawaimul1,2, M. G. Sahare ${ }^{1,2}$, S. Z. Ali², A. R. Sirothia ${ }^{2}$ and Satish Kumar ${ }^{1}$
}

1. Animal Biotechnology Section, Central Sheep and Wool Research Institute, Avikanagar, Rajasthan, India;

2. Department of Animal Genetics and Breeding, Nagpur Veterinary College, Nagpur, Maharastra, India.

Corresponding author: Dr. Satish Kumar, e-mail: biotech.satish@gmail.com, ADS: aviratsawaimul@gmail.com, MGS: drmaheshagb@gmail.com, SZA: szali@rediffmail.com, ARS: arsirothia@gmail.com

Received: 10-06-2014, Revised: 13-09-2014, Accepted: 20-09-2014, Published online: 19-10-2014

doi: 10.14202/vetworld.2014.852-855. How to cite this article: Sawaimul AD, Sahare MG, Ali SZ, Sirothia AR, Kumar S (2014) Assessment of genetic variability among Indian sheep breeds using mitochondrial DNA cytochrome-b region, Veterinary World 7(10): 852-855.

\begin{abstract}
Aim: The present study was conducted to estimate genetic distance, the phylogenetic relationship, and time of divergences using mitochondrial DNA (mtDNA).

Materials and Methods: The total 216 unrelated samples were collected from native breeding tract of six Indian sheep breeds. The genomic DNA was isolated and screened for restriction enzyme polymorphisms for cytochrome b (Cyt-b) region of mtDNA with seven restriction enzymes.

Results: The genetic distance among sheep breeds was ranging between 0.02833 and 0.0946 . The phylogenetic analysis revealed that Malpura and Chokla were found closer relationship forming distinct cluster followed by Deccani individual were clustered with Nellore sheep, whereas Nali and Sonadi were distant to each other having separate cluster. Estimated divergence time among Indian sheep breeds were ranging about 1.41-4.73 million years ago (MYA) with an average of 3.063 \pm 0.27 MYA. It showed that Malpura and Sonadi sheep revealed highest divergence time as 4.73 MYA whereas Malpura and Chokla show the lowest as 1.41 MYA.

Conclusion: In conclusion, the restriction fragment length polymorphisms-polymerase chain reaction (RFLP-PCR) of the Cyt-b region of mtDNA is suitable and cost effective tool for estimating the genetic variability, phylogenetic relationship, and time of divergence among Indian sheep breeds. These findings will help to formulate proper breeding strategies for conservation and utilization of sheep breeds.
\end{abstract}

Keywords: genetics-diversity, mitochondrial DNA, restriction fragment length polymorphisms-polymerase chain reaction, sheep breed.

\section{I ntroduction}

In India, the genetic diversity of sheep breeds is declining and results in breed dilution due to crossbreeding policy, intercrossing of sheep germplasm, and modern agricultural practices. Information on genetic variability among breeds may help in the development of breeding programs and is a prerequisite for conservation of genetic resources and germplasm [1].

The structure and function of mitochondrial DNA (mtDNA) have been a popular area of research in molecular evolution, classification, population genetics analysis, aging, disease diagnosis, apoptosis, and the analysis of quantitative trait loci [2]. At present, mtDNA plays an important role in estimating the genetic diversity and phylogenetic relationship in livestock species including sheep [3]. The cytochrome b (Cyt-b) is an essential part of the mtDNA and has been used for the identification of species' differences and divergence time between species or in breeds [4]. Previously, the genetic diversity and the phylogenetic

Copyright: The authors. This article is an open access article licensed under the terms of the Creative Commons Attributin License (http:// creative commons.org/licenses/by/2.0) which permits unrestricted use, distribution and reproduction in any medium, provided the work is properly cited. evolution of Chinese sheep breeds have studied using Cyt-b gene [5].

The purpose of this study was to estimate the genetic diversity, phylogenetic relationship, and time of divergence among Indian sheep breeds using the Cyt-b region mtDNA.

\section{Materials and Methods}

Ethical approval

The blood samples were collected as per standard procedure.

\section{Experimental animals}

A total 216 blood samples of six sheep breeds viz. Deccani, Nellore, Malpura, Chokla, Nali and Sonadi was taken into consideration. $5 \mathrm{ml}$ blood was collected from unrelated individuals of each breed belonging to their native breeding tract. The blood samples were transported to the laboratory and stored at $4^{\circ} \mathrm{C}$. The genomic DNA was isolated using phenol-chloroform extraction method [6].

\section{Polymerase chain reaction (PCR) amplification of mtDNA Cyt-b gene}

The mtDNA Cyt-b region was amplified by primer pairs designed on the basis of available ovine mtDNA sequence Acc. No. AF 010406 [7]. The synthesized primer is as follows: Cyt-b F Forward 
5'CATTGATCTCCCAGCTCCA3' and reverse Cyt-b R 5'GATGTAGGGGTGTTCAACTGG3'. The reaction conditions were optimized in $50 \mu \mathrm{l}$ volume reaction volume comprising; $1 \times$ PCR buffer (NH4) 2SO4, $1.5 \mathrm{mM}$ MgCl2, $100 \mu \mathrm{M}$ dNTPs mix, 1.25 U Taq DNA polymerase, $100 \mathrm{nM}$ of each primer, and $50 \mathrm{ng}$ of DNA. The gradient PCR was carried out with the different annealing temperatures $\left(58-62^{\circ} \mathrm{C}\right)$, and it was observed that annealing temperature of $61^{\circ} \mathrm{C}$ gave the best result. The amplification conditions were as follows; initial denaturation $95^{\circ} \mathrm{C}$ for $5 \mathrm{~min}$ (one cycle) followed by denaturation at $95^{\circ} \mathrm{C}$ for $30 \mathrm{~s}$, annealing at $61^{\circ} \mathrm{C}$ for $30 \mathrm{~s}$, extension at $72^{\circ} \mathrm{C}$ for $45 \mathrm{~s}$ for 34 cycles with a final extension at $72^{\circ} \mathrm{C}$ for $5 \mathrm{~min}$. The amplified PCR product was run on $2.5 \%$ agarose gel at $100 \mathrm{~V}$ for $2 \mathrm{~h}$.

\section{Screening the different restriction enzymes}

The amplified PCR product of Cyt-b region were screened for different restriction enzymes as Alu I, Ssp I, Taq I, Sac I, Mbo II, Bam HI and Rsa I. Digestion reaction per sample was set up in $5 \mu \mathrm{l}$ reaction volume containing $10 \times$ buffer $(1.0 \mu \mathrm{l})$, restriction enzyme $(10 \mathrm{U} / \mu \mathrm{l})(0.1 \mu \mathrm{l})$ and Milli Q water $(3.9 \mu \mathrm{l})$. The $5 \mu$ PCR product was taken, and equal volume of the digestion mixture was added. The PCR content was gently mixed by pipetting and incubated at least for $3 \mathrm{~h}$. The digested products were run in a $2.5 \%$ agarose gel in 1\% tris-borate-EDTA buffer. A 100 bp DNA ladder (MBI FERMENTAS) was also run along with the sample. The digested product was visualized and documented by Gel documentation system.

\section{Analysis of molecular data}

The samples are categorized in six sets, each set comprising 36 individuals (six individuals from each breed) in order to Deccani, Nellore, Malpura, Chokla, Nali and Sonadi. The generated restriction fragment length polymorphisms (RFLP) band profiles in each set were scored for their presence (1) or absence (0) and prepared binary data files. These RFLP band profile binary data files were utilized for estimation of genetic distance and phylogenetic tree using unweighted pair-group method with arithmetic mean analysis through neighbor procedure by POPGENE software program version 3.5 c [8] using standard genetic distance equation [9].

The divergence time $(\mathrm{t})$ was estimated using molecular clock equation given by Nei [9]. $\lambda=d / 2 t$ Where, $\lambda$ (substitution rate per nucleotide site per year). $d$ (mean genetic distance between individual within the group or between groups). $t$ (divergence time between individual within the group or between).

A sequence divergence of $\sim 2 \%$ per million years for mtDNA has been reported among mammalian species, corresponding to a nucleotide substation rate of $1 \times 10^{-8}$ substation/site/year in lineage [10].

\section{Results and Discussion}

MtDNA provides a better understanding about the genetic diversity and phylogenetic analysis of the sheep breeds than any conventional markers. Enzymes showing distinct band profiles; Alu I ( $(\mathrm{n}=2)$, Ssp I $(\mathrm{n}=3)$, Taq I $(\mathrm{n}=2)$, Sac I ( $\mathrm{n}=5)$, Mbo II $(\mathrm{n}=2)$, Bam HI $(\mathrm{n}=4)$, and Rsa I $(\mathrm{n}=4)$ utilized for screening of all six set of Deccani, Nellore, Malpura, Chokla, Nali, and Sonadi sheep breeds (Figures-1 and 2). On the basis of RFLP pattern, the genetic distance was estimated are shown in Table-1. In the present study, RFLP-PCR profile of the Cyt-b region in all set produces the varied results. Hence, the data of all six sets were pooled for estimation of genetic distance, and phylogenetic relationship gave the most reliable results.

The overall genetic distance was the lowest between Malpura and Chokla breed. The results indicated that Malpura and Chokla are closer to each other, this might be due to fact that both breeds belongs to the same geographical region (northwestern arid and semi-arid region of Rajasthan) represented less variation in the Cyt-b gene. In contrast, microsatellite marker analysis suggested that Nali is closer to Chokla than the Garole sheep [11]. It is highly unlikely that Garole sheep may not have resemblances to Nali or Chokla breeds; therefore, the similarity between the Nali and Chokla would be closer. It has been suggested that the individuals of Chokla breed might have some resemblances with the Malpura sheep due to the crossbreeding/intermixing of these breeds in the neighboring areas adopting by the farmers.

The Malpura breed showed the highest genetic distance with Sonadi sheep. The Malpura and Sonadi sheep are belonging to same geographic zones, northwestern arid and semi-arid region of Rajasthan. The

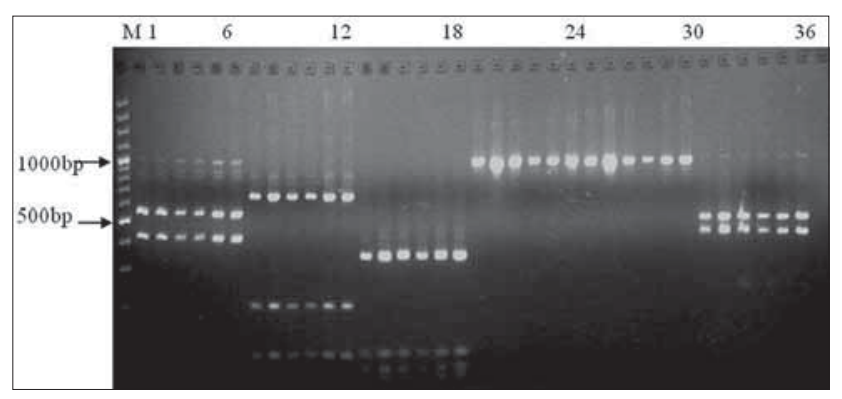

Figure-1: Screening of mitochondrial cytochrome $b$ of sheep pooled DNA revealed by four restriction enzyme. Lane 1-6 Ssp I, lane 7-12 Alu I, lane 13-18-Hae III, lane 17-24 Taq I, lane 25-30 Hph I, and lane 31-36 Sca I.

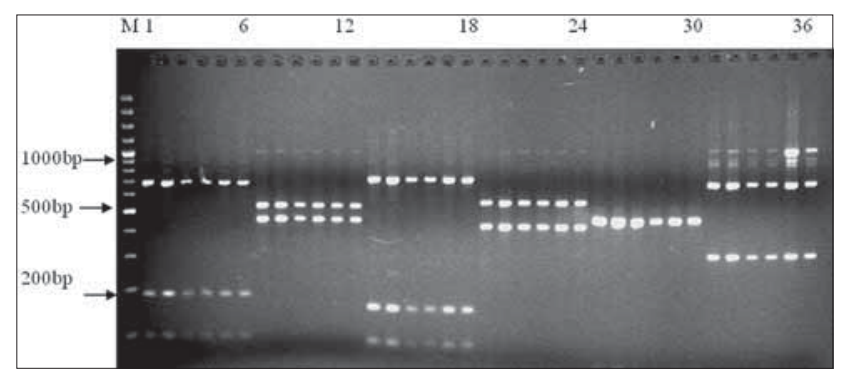

Figure-2: Screening of mitochondrial cytochrome $b$ of sheep pooled DNA revealed by four restriction enzyme. Lane 1-6 Bam HI, lane 7-12 Rasa I, lane 13-18-Hinf I, lane 17-24 Dpn I, lane 25-30 Msp I, and lane 31-36 Mbo II. 
possible reason may be due to both breeds might have different genetic background and have a variation in the gene pool, but these variations may not affect the phenotype in pronouncedly thereby both sheep have almost same phenotypic characteristics. Since Deccani and Nellore breeds have showed the lower genetic variability among them. The results indicated that the individuals of Deccani sheep clustered into Nellore sheep, which is indicating that both breeds have some resemblances to each other. Previously, the genetic diversity estimated by using randomly amplified polymorphic DNA (RAPD)-PCR among Marwari, Mandya, Madras Red and Muzaffaranagari sheep were studied by Kumar et al. [12]. The genetic distance among these breeds was ranged from 0.0761 to 0.1906 . In the present study, the overall genetic distance was found lower than that the distance found in Indian sheep breeds by RAPD-PCR technique.

The dendrogram of pooled data set of six sheep breeds are shown in Figure- 3 as well the estimated divergence time on the basis of genetic distance of pooled data set is given in Table-2. The phylogenetic tree revealed that Malpura individuals clustered with Chokla followed by Deccani with Nellore sheep. The Deccani and Nellore sheep belongs to the peninsular region of the country. The Deccani and Nellore sheep belongs to the peninsular region of the country. Both Deccani and Nellore breeds are distributed in the similar type of climatic conditions, thereby having close resemblances in the phenotypes. Both breeds are mutton type and hairy. The Nali and Sonadi sheep fall into separate clade, which indicating that these breeds belong to same geographical zones, northwestern arid and semi-arid region of Rajasthan. Both breeds have phenotypic resemblances like fleece is completely white, and both are reared for dual purposes like meat and wool.

The divergence time of Indian Sheep ranges from 1.41 to 3.84 million years ago (MYA) with an average of about $3.063 \pm 0.27$ MYA. The Cyt-b gene is considered more accurate for calibrating a molecular clock among mtDNA lineages in livestock species, because its pattern of evolution is well understood and presumably relatively constant among most mammal species [13]. The divergence time about 375,000-750,000 year ago, among the European and Asian domestic sheep based on the mtDNA was given by Hiendleder et al. [14]. This study indicated that European and Asian domestic sheep breeds might diverge since the process of domestication. The

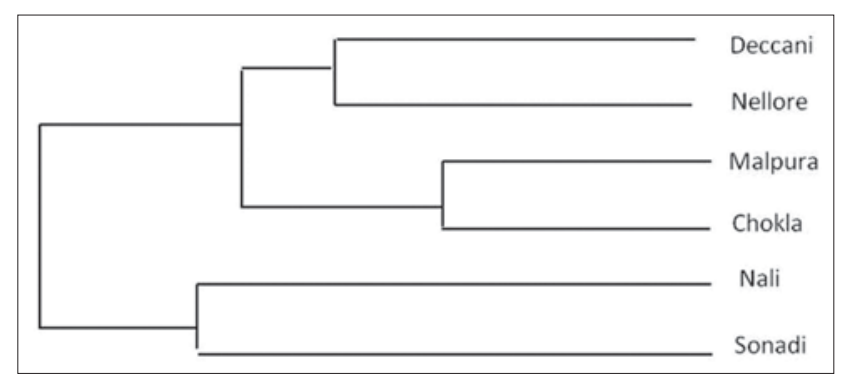

Figure-3: Dendrogram based on genetic distance of mitochondrial DNA cytochrome $b$ region.

Table 1: Estimated genetic distance in all sets among six sheep breeds.

\begin{tabular}{|c|c|c|c|c|c|c|}
\hline \multirow{2}{*}{$\begin{array}{l}\text { Breed } \\
\text { comparisons }\end{array}$} & \multicolumn{6}{|c|}{ Genetic distance } \\
\hline & Set 1 & Set 2 & Set 3 & Set 4 & Set 5 & Set 6 \\
\hline Deccani-Nellore & 0.0172 & 0.0016 & 0.0466 & 0.0520 & 0.0447 & 0.0497 \\
\hline Deccani-Malpura & 0.0465 & 0.0010 & 0.0438 & 0.0677 & 0.0820 & 0.0725 \\
\hline Deccani-Chokla & 0.0196 & 0.0120 & 0.0588 & 0.0599 & 0.0348 & 0.1242 \\
\hline Deccani-Nali & 0.0324 & 0.0438 & 0.0780 & 0.1127 & 0.0479 & 0.1344 \\
\hline Deccani-Sonadi & 0.0503 & 0.0895 & 0.0402 & 0.1417 & 0.0592 & 0.1228 \\
\hline Nellore-Malpura & 0.0631 & 0.0028 & 0.0367 & 0.0244 & 0.0317 & 0.0401 \\
\hline Nellore-Chokla & 0.0552 & 0.0132 & 0.0349 & 0.0418 & 0.0150 & 0.0980 \\
\hline Nellore-Nali & 0.0585 & 0.0403 & 0.0691 & 0.1457 & 0.0337 & 0.0851 \\
\hline Nellore-Sonadi & 0.0434 & 0.0973 & 0.0629 & 0.1472 & 0.0379 & 0.1370 \\
\hline Malpura-Chokla & 0.0599 & 0.0082 & 0.0127 & 0.0142 & 0.0199 & 0.0493 \\
\hline Malpura-Nali & 0.0701 & 0.0365 & 0.0614 & 0.1436 & 0.0654 & 0.0913 \\
\hline Malpura-Sonadi & 0.0617 & 0.0795 & 0.0458 & 0.1433 & 0.0810 & 0.1597 \\
\hline Chokla-Nali & 0.0180 & 0.0125 & 0.0630 & 0.0871 & 0.0304 & 0.1311 \\
\hline Chokla-Sonadi & 0.1084 & 0.0627 & 0.0609 & 0.0870 & 0.0431 & 0.1049 \\
\hline Nali-Sonadi & 0.1151 & 0.0543 & 0.0416 & 0.0247 & 0.0089 & 0.0683 \\
\hline
\end{tabular}

Table-2: Overall genetic distance (below diagonal) and divergence time million years ago (above diagonal) among sheep breeds.

\begin{tabular}{lcccccc}
\hline Population & Deccani & Nellore & Malpura & Chokla & Nali & Sonadi \\
\hline Deccani & $* * * *$ & 1.75 & 2.58 & 2.60 & 3.76 & 4.15 \\
Nellore & 0.0350 & $* * * *$ & 1.67 & 2.18 & 3.51 & 4.32 \\
Malpura & 0.0516 & 0.0334 & $* * * *$ & 1.41 & 3.84 & 4.73 \\
Chokla & 0.0520 & 0.0436 & 0.0283 & 0.0574 & 2.87 & 3.90 \\
Nali & 0.0752 & 0.0703 & 0.0768 & 0.0780 & 0.0536 & 2.68 \\
Sonadi & 0.0830 & 0.0865 & 0.0946 & & & $* * * *$ \\
\hline
\end{tabular}


phylogenetic estimates and divergence time using RFLP of mtDNA of cattle breeds was determined by about a 575,000 and 1150,000 year ago [15]. Similarly [16], analyzed 10 goat breeds of India based on the control D-loop sequence and the divergence time estimated to be in between 201,000 and 280,000 years. The analysis of divergence time using Cyt-b region of mtDNA of goat breeds was about 201,380281,932 years [17].

\section{Conclusion}

The Cyt-b region of mtDNA using RFLP-PCR technique was suitable tool for analyzing genetic variability, phylogenetic relationship, and time of divergence among the Deccani, Nellore, Malpura, Chokla Nali, and Sonadi sheep breeds. Further study is required to sequence the complete region of Cyt-b region of sheep breed to understand the genetic architecture of Indian sheep breeds which will able us to formulate and adopt an appropriate strategies for conservation and further utilization of the sheep breeds for the improvement of the sheep productivity in the country.

\section{Authors' Contributions}

AD, SK, SA designed the study. SK, AD and MG collected samples and performed experiments. MG and SK wrote the manuscript. AS is in an advisory committee of MVSC thesis work submitted by AD. All authors read the manuscript and approved the final manuscript.

\section{Acknowledgments}

The authors are thankful to the Director, Central Sheep and Wool Research Institute, Avikanagar for providing necessary facilities and fund for carrying out this study. The authors thanks to Dr. S. Deshpande, Dr. Shivanand Ghule, Dr. Sunil More, and Dr. Kuldeep Hadole for their assistance in collection of the blood sample from the field tract.

\section{Competing I nterests} interests.

The authors declare that they have no competing

\section{References}

1. Taberlet, P., Coissac, E., Pansu, J. and Pompanon, F. (2011) Conservation genetics of cattle, sheep, and goats. C. R. Biol., 334(3): 247-254.

2. Zhao, E., Yu, Q., Zhang, N., Kong, D. and Zhao, Y. (2013)
Mitochondrial DNA diversity and the origin of Chinese indigenous sheep. Trop. Anim. Health Prod., 45: 1715-1722.

3. Oner, Y., Calvo, J.H. and Elmaci, C. (2013) Investigation of the genetic diversity among native Turkish sheep breeds using mtDNA polymorphisms. Trop. Anim. Health Prod., 45: 947-951.

4. Haus, T., Akom, E., Agwanda, B., Hofreiter, M., Roos, C. and Zinner, D. (2013) Mitochondrial diversity and distribution of African green monkeys (chlorocebus gray, 1870). Am. J. Primatol., 75(4): 350-360.

5. Wang, X., Ma, Y.H. and Chen, H. (2006) Analysis of the genetic diversity and the phylogenetic evolution of Chinese sheep based on Cyt-b gene sequences. Yi Chuan Xue Bao, 33: 1081-1086.

6. Meena, A.S., Kumar, R., Kumari, R., Jyotsana, B., Prince, L.L.L. and Kumar, S. (2013) Genetic polymorphism of melatonin receptor 1A (MTNR1A) gene in Indian sheep breeds. Indian J. Anim. Sci., 83: 1284-1287.

7. Hiendleder, S., Lewalski, H., Wassmuth, R. and Janke, A. (1998) The complete mitochondrial DNA sequence of domestic sheep (Ovis aries) and comparison with other major ovine haplotype. Mol. Evol., 47: 441-448.

8. Yeh, F.C., Yang, R.C. and Boyle, T. (1999) Popgene, Version 1.32. The user-friendly freeware for population genetic analysis. Molecular Biology and Biotechnology Centre, University of Alberta, Canada.

9. Nei, M. (1972) Genetic distance between populations. Am. Nat., 106: 283-292.

10. Brown, W.M., George M. and Wilson A.C. (1979) Rapid evolution of mitochondrial DNA. Proc. Natl. Acad. Sci. USA, 76: 1967-1971.

11. Mukesh, M., Sodhi, M. and Bhatia, S. (2006) Microstallitebased diversity analysis and genetic relationship of three Indian sheep breeds. J. Anim. Breed Genet., 123(4): 258-264.

12. Kumar, G.K., Kumar, P., Kumar, S., Bhattacharya, T.K., Bhusan, B. and Ahlawat, S.P.S. (2004) Randomly amplified polymorphic DNA (RAPD) fingerprinting of Indian Sheep breeds. Indian J. Anim. Sci., 74(8): 860-863.

13. Bibi, F. and Vrba, E.S. (2010) Unraveling bovine phylogeny: Accomplishments and challenges. BMC Biol., 29: 8-50.

14. Hiendleder, S., Mainz, K., Plante, Y. and Lewalski, H. (1998) Analysis of mitochondrial indicates that domestic sheep are derived from two different ancestral maternal sources: No evidence for contribution from urial and argali sheep. J. Hered., 89: 113-120.

15. Loftus, R.T., MacHugh, D.E., Ngere, L.O. Balain, D.S. Badi, A.M. Bradley, D.G. and Cummingham, E.P. (1994) Mitochondrial genetic variation in European African and Indian cattle population. Anim. Genet., 25(4): 265-271.

16. Joshi, M.B., Rout, P.K., Mandal, A.K., Tyler-Smith, C. and Singh, L. (2004) Phylogeography and origin of Indian domestic goats. Mol. Biol. Evol., 21: 452-462.

17. Luikart, G. Giellly, L. Excoffier, L. Vigne, J.D. Bouvet, J. and Taberlet, P. (2001) Multiple maternal origin and weak phylogeographics structure in domestic goats. Proc. Natl. Acad. Sci. USA, 98: 5927-5932. 